\title{
Historia geográfica, natural y civil del Reino de Chile (1782) del jesuita expulso Felipe Gómez de Vidaurre: una obra injustamente desvalorizada por la historiografía chilena/
}

\author{
Historia Geográfica, Natural y Civil del Reino de Chile (1782) \\ of the Jesuit Expelled Felipe Gómez de Vidaurre: \\ a Work Unjustly Devalued by Chilean Historiography
}

\author{
Marcos A. Figueroa Zúñiga \\ ORCID iD: http://orcid.org/0000-0002-5415-7607 \\ Universidad de Santiago de Chile
}

Este trabajo intentará presentar la Historia geográfica, natural y civil del Reino de Chile del jesuita chileno expulso Felipe Gómez de Vidaurre, que a pesar de que haya sido olvidada por la historiografía chilena contiene interesantes descripciones de los habitantes del Chile de fines del siglo XVIII y algunas propuestas para mejorar aspectos de la sociedad chilena, que la convierten en un texto valioso para comprender el periodo que precede a la independencia de Chile.

Palabras clave: Jesuita expulso; Reino de Chile; Siglo XVIII; Mártir de la Independencia.

This paper will attempt to present the Historia geográfica, natural y civil del Reino de Chile by the Chilean Jesuit expelled Felipe Gómez de Vidaurre, that despite being forgotten by the Chilean historiography it contains interesting descriptions of the inhabitants of Chile in the late eighteenth century. It also offers some proposals to improve aspects of Chilean society, which makes it a valuable text for understanding the period preceding the independence of Chile.

KeYwords: Jesuit expelled; Kingdom of Chile; Eighteenth Century, Martyr of the Independence.

Copyright: (C) 2017 CSIC. Este es un artículo de acceso abierto distribuido bajo los términos de una licencia de uso y distribución Creative Commons Attribution (CC-by) España 3.0. 


\section{La expulsión y la escritura}

El respeto que debo no me permite pasar adelante, principalmente con el justo temor de ofender la moderación de V. Exa., por lo que concluyo suplicándole a admitir la presente dedicatoria, como un acto, no tanto de obediencia a sus órdenes, que sino de particular adhesión a su persona, que Dios prospere para felicidad de la América y de la Corona, conservando su vida por muchos años. ${ }^{1}$

Este fragmento, que corresponde a la dedicatoria que Felipe Gómez de Vidaurre Girón hace en su obra a Antonio Porlier, secretario de Estado y del Despacho de Gracia y Justicia de España y de Indias, y en el que se enfatizan los agradecimientos a la persona más que al ministro de Estado, puede ser considerado como una muestra de su molestia hacia la administración española, pues este jesuita y criollo chileno, nacido en la ciudad de Concepción en $1740^{2}$ en una de las más antiguas y prósperas familias del periodo colonial chileno, fue parte del grupo de alrededor de trescientos cincuenta religiosos pertenecientes a la provincia de la Compañía de Jesús de Chile que partieron al exilio a comienzos de 1768, luego de conocerse el decreto de expulsión de la orden ignaciana para los territorios pertenecientes a la monarquía española, emitido un año antes por el rey Carlos III.

Los primeros años de su exilio los vivió en Imola, ciudad italiana donde se destinó a la mayoría de los jesuitas provenientes de Chile, por lo que pudo compartir con otros expulsos importantes para las letras chilenas, como Juan Ignacio Molina, Manuel Lacunza y Miguel de Olivares. En los primeros años de exilio en Imola los jesuitas pudieron transitar una suerte de normalidad, que en parte se debía a la subsistencia de la Compañía de Jesús, pero principalmente por el buen manejo de los provinciales Baltasar Huever y Francisco Javier Varas, que lograron mantenerlos reunidos (viviendo en comunidad) y en buenas condiciones. ${ }^{3}$ Por ejemplo, Vidaurre

1 Vidaurre, 1889 [1782], I, 2. El destacado es nuestro.

2 Se manejan algunas fechas posibles de nacimiento, principalmente el año 1748, señalada por José Toribio Medina en la «Introducción» que hace de la obra del expulso para la edición de 1889 , seguida por algunos autores posteriores y que parece ser equivocada. Este error pudo deberse al calcular mal la edad que tendría el jesuita al momento del expulsión de la Compañía, pues toma como fuente un documento que contiene la nómina de los jesuitas expulsos chilenos donde se señala que Vidaurre al momento de la detención (1767) tenía 28 años. (Medina, 1889, IX). Si se utiliza como referencia ese documento, la fecha de nacimiento se aproximaría más a 1739 o 1740 y no a 1748, como indica Medina. Walter Hanisch $(1972,229)$ señala que el jesuita nació el 1. ${ }^{\circ}$ de mayo de 1740, fecha que puede ser la más probable, pues al momento de la expulsión el jesuita chileno enseñaba gramática en el Colegio Máximo de Santiago, y no creemos posible que esto lo hiciera a la temprana edad de 19 años, que habría tenido si hubiese nacido en 1748 .

3 Hanisch, 1972, 82. 
en este periodo finalizaría su profesión de votos y comenzaría a escribir su Historia. $^{4}$

Después de la supresión de la Compañía, decretada en 1773 por el Papa Clemente XIV, la situación emporó para la mayoría de los expulsos. El ecuatoriano Juan de Velasco nos entrega uno de los pocos testimonios en primera persona que se pueden leer respecto a este triste momento de los padres jesuitas, recordemos que entre las prohibiciones que contenía la Real Pragmática Sanción de 1767 para los expulsos, y a riego de perder la pensión vitalicia, no se podía escribir, imprimir o declamar sobre el asunto del extrañamiento, ${ }^{5}$ en un capítulo inédito de su Historia moderna del Reyno de Quito y crónica de la Provincia de la Compañía de Jesús del mismo Reyno, Velasco señala:

Cada cual tiró libremente por aquel camino que le deparó la casualidad, la fortuna o la natural inclinación. Unos se aplicaron a enseñar a leer y escribir, o la Gramática o alguna otra facultad o ciencia, en privado o tal vez en público; otros a confesar y aun predicar donde lo gustasen y querían los Obispos; otros a escribir sobre diversas materias, de modo que no hubo arte, facultad, ni ciencia sobre la que no diesen a la luz tantas y tan excelentes obras que han merecido los comunes aplausos y podrán formar ellas solas una muy selecta y cumplida biblioteca. Unos se aplicaron a contratar con algunas frioleras y otros a moler tabaco o chocolate, para ganar algo con los mismos Españoles. Unos de los que vinieron de Escolares y Coadjutores se dieron modo a ordenarse de Sacerdotes; y otros se fueron casando, más casi todos infelizmente. Los que no eran capaces de aquellas ocupaciones o no quisieron emplearse en ellas, se aplicaron unos a sólo leer libros, otros a sólo cuidar de sus almas, y otros a consumir en la inacción y el ocio el resto de sus tristes y amargos días. ${ }^{6}$

Considerando que Imola ya no seguiría siendo el refugio de esos primeros años de exilio y que la pensión que suministraba la Corona era insuficiente e impuntual, Vidaurre y su colega (y amigo) Juan Ignacio Molina decidieron trasladarse a la vecina ciudad de Bolonia a comienzos de 1774. Esta ciudad ofrecía para estos letrados americanos mayores horizontes desde el punto de vista material y cultural, ya que por aquella época seguía siendo un centro académico importante. Si bien casi no existen noticias de la vida de Vidaurre en esta ciudad, se pueden utilizar como referencia algunas de las actividades que realizó allí el abate Molina, que han concitado mayor interés para la historiografía chilena, ${ }^{7}$ por lo que podemos inferir

4 Ibidem, 228-229.

5 Medina Rojas, 2007, 460.

6 Cit. en Espinosa Pólit, 1989, 101-102.

7 Al final de este trabajo intentaremos organizar algunos datos de sus últimos años de vida, ya de vuelta a Chile y en pleno periodo de la emancipación. 
que en Bolonia nuestro autor mayormente realizó algunas actividades para mejorar su renta — como hacer clases privadas - ${ }^{8}$ y terminó de redactar su obra. También es probable que en los primeros años su actividad más importante haya sido redactar, posiblemente junto a Molina, el Compendio della storia geografica, naturale, e civili del regno del Chile (1776), ${ }^{9}$ el llamado «Compendio anónimo», tan admirado por Francisco de Miranda y recomendado por el propio libertador americano a Thomas Jefferson, tercer presidente de Estados Unidos. ${ }^{10}$

La escritura de la Historia geográfica, natural y civil del Reino de Chile Vidaurre la emprende motivado por el desconocimiento que existía en Europa a fines del siglo XVIII de la por entonces Capitanía General de Chile y por la degradada imagen que habían construido de este territorio, como del resto de América, algunos sabios europeos. ${ }^{11} \mathrm{El}$ primero era un objetivo que se venía enunciando desde mediados del siglo XVII, principalmente en la Histórica Relación del Reino de Chile (1646) de Alonso de Ovalle, otro jesuita chileno, ${ }^{12}$ y el segundo, que más bien consistía en un rebrote de la «leyenda negra antiespañola» en la Europa del siglo XVIII, ayudó a perfilar discursivamente los trabajos de los escritores jesuitas criollos y expulsos hacia una defensa de lo americano.

Estos jesuitas expulsos criollos, como el mexicano Francisco Javier Clavijero, el ecuatoriano Juan de Velasco, el chileno Juan Ignacio Molina y el propio Vidaurre, no podían defender lo americano e inmiscuirse en una

8 Esto es más que probable, ya que para el tiempo de la expulsión Vidaurre se desempeñaba como profesor de gramática en el Colegio Máximo de Santiago. Hanisch, 1972, 228. Tampe, 2008, 269. Vidaurre en su Historia se referirá someramente de esta labor cuando trata de los métodos de enseñanza para los jóvenes criollos. Vidaurre, 1889 [1782], II, 291.

9 Esta obra anónima y escrita originalmente en italiano, fue publicada en la Imprenta de Tommaso D’Aquino de la ciudad Bolonia en 1776. La edición alemana del «Compendio anónimo» de 1782, traducida por Cristian Joseph Jägermann y publicada en Hamburgo en la editorial Ben Carl Ernst Bohn, se la atribuye a Felipe Gómez de Vidaurre. Sin embargo, en Chile ha existido siempre el consenso que esta obra fue escrita por Juan Ignacio Molina, por ejemplo, la única edición chilena, traducida por Narciso Cueto y publicada en 1878, se la adjudica a Molina, mismo parecer de Diego Barros Arana, que además intenta demostrarlo (con escaso éxito) en su Historia jeneral de Chile. Barros Arana, 18841902, VII, 533. Vidaurre colabora con esta incertidumbre, primero en su Historia (1889, II, 296) al expresar que «su autor, chileno, enemigo de gloria, ocultó su nombre y no quiere que salga aún en esta», y posteriormente adjudicándosela en una carta (avalado con un «instrumento jurídico») que dirige en 1793 al secretario de Gracia Justicia Juan Acedo-Rico para solicitar una doble pensión. Hanisch, 1976, 175-176. En la revisión que hemos hecho del «Compendio anónimo» para las investigaciones de una tesis de maestría acerca de Juan Ignacio Molina, no pudimos encontrar un claro estilo de escritura que permita establecer que pertenezca únicamente a uno de estos jesuitas expulsos.

10 Batllori, 1995, 88-89.

11 Vidaurre, 1889, I, 3.

12 Figueroa, 2012, 23. 
disputa intelectual con los europeos validando y defendiendo lo realizado por España en América durante casi tres siglos de coloniaje; asimismo, no podían ser abiertamente críticos con la administración española, por la sencilla razón de poner en riesgo la pensión vitalicia, que para muchos de ellos era el único dinero con el que contaban para solventar los gastos básicos. Esta dificultad discursiva la resuelven al orientar sus trabajos principalmente en hacer una descripción detallada de la naturaleza y de las culturas originarias de sus respectivos países, como también, particularmente en el caso de Juan Ignacio Molina, pero extrapolable al resto de expulsos citados, confiriéndole a lo nacional y autóctono una validez universal, argumentando que las sociedades americanas no son degeneradas e inferiores, sino que han tenido un ritmo de progreso distinto. ${ }^{13}$

Para el filósofo argentino Arturo Andrés Roig estas polémicas dieron como resultado uno de los primeros ensayos en los que hombre americano se hizo cargo de su representación e historicidad, en cuyo trabajo utilizó el mismo lenguaje del europeo, ${ }^{14}$ pero con una intencionalidad claramente distinta. ${ }^{15}$ Federico Álvarez Arregui sostiene que «leyendo estas obras el lector se da cuenta de que constituyen algo así como la primera conciencia americana o, al menos, un incipiente orgullo criollo», pues, si bien, lo específico americano venía perfilándose progresivamente desde «los primeros vagidos del peculiarísimo barroco americano hasta la insurrección de Túpac Amaru», es a través de estos jesuitas que el «ser americano abre una nueva etapa en su desarrollo hacia una plena autoconciencia y adquiere un perfil mucho más concreto». ${ }^{16}$ Habría que agregar que este «autorreconocimiento» — parafraseando a Roig — de los criollos jesuitas se aceleró por los especiales hechos históricos que les tocó vivir directamente, como la expulsión de la Orden del continente americano y su posterior supresión y el desarrollo de la Ilustración en el último cuarto del siglo XVIII (que absorbieron en escenario europeo), así como también otros más personales, pero no menos importante para este proceso, como su calidad de exiliados en Europa y el orgullo ignaciano incrementado por el proyecto interrumpido.

Es así como Vidaurre, de la misma forma que los jesuitas expulsos más connotados, eso sí, con menos insistencia, discute el determinismo geográfico propuesto por algunos pensadores europeos para el continente

13 Figueroa, 2008, 96.

14 Muchas de las historias civiles y naturales que escribieron estos jesuitas se ajustaban a los más estrictos cánones científicos de la época.

15 Roig, 2009, 150.

16 Álvarez Arregui, 1994, 48. 
americano, que por lo demás afectaba directamente a los criollos. Por ejemplo, le impugna a Cornelius de Pauw $^{17}$ algunas de sus falaces teorías, como que la naturaleza americana es inferior y que sus especies, tanto vegetales como animales, degeneran rápidamente. Además, le responde con ejemplos que ha obtenido de manera directa o con los que ha recogido de otros autores que han visitado los territorios americanos, como los españoles Antonio de Ulloa y José de Acosta y los viajeros franceses Amadeo Frezier y Louis Feuillée, recriminando la irresponsabilidad del filósofo holandés al injuriar territorios que conoce solo de segunda mano. ${ }^{18}$

\section{Las vicisitudes de Historia geográfica, natural y civil del Reino de Chile}

Por la notoriedad que estaba adquiriendo Juan Ignacio Molina en Europa, principalmente por la edición de su Saggio sulla storia naurale del Chili (1782), ${ }^{19}$ el ministro Porlier comenzó a solicitar a los jesuitas expulsos sus trabajos para una futura publicación. Vidaurre al parecer no tenía mayores intenciones de hacer publicar su obra, pues el manuscrito de esta circulaba entre sus colegas como material de lectura desde 1782, año en que habría finalizado su redacción. Sin embargo, en 1788 le escribe a Luis Gnecco, comisario real y uno de los encargados de vigilar a los jesuitas expulsos en Bolonia, señalándole que después de recuperar su obra y de hacer los últimos arreglos la enviará a España; lo hace el 20 de enero de $1789 .{ }^{20}$

A pesar de estos áulicos intentos Historia geográfica, natural y civil del Reino de Chile no se publicaría en aquella época en España, sino recién en 1889 en Chile, en los volúmenes XIV y XV de la Colección de Historiadores de Chile y de Documentos Relativos a la Historia Nacional ${ }^{21}$ y con

17 Cornelius Franciscus de Pauw fue un filósofo holandés, autor de Recherches philosophiques sur les Américains, publicado en dos volúmenes en Berlín, en 1768 y1769. Este libro marca uno de los puntos iniciales de la polémica intelectual de finales del siglo XVIII, que el investigador italiano Antonello Gerbi ha denominado como «la disputa del Nuevo Mundo», en su clásico libro del mismo nombre publicado en 1955. El libro de De Pauw estaba influenciado por las ideas de la Histoire naturelle, del importante naturalista francés Georges Louis Leclerc, Conde de Buffon, publicada entre 1749 y 1788.

18 Vidaurre, 1889, I, 165.

19 Saggio sulla storia naturale del Chili, escrito originalmente en italiano, fue publicado en Bolonia en 1782 en la Imprenta de Tommaso D’Aquino. Tuvo traducciones al alemán, francés, inglés, español, etc. La edición en español de esta obra fue traducida por Domingo Joseph de Arquellada Mendoza, con el título Compendio de la historia geográfica, natural y civil del reyno de Chile, y publicada en Madrid en 1788 en la Imprenta de Antonio de Sancha.

20 Hanisch, 1972, 228.

21 Desde ahora en adelante $\mathrm{CHCH}$. 
un trabajo introductorio de José Toribio Medina. El manuscrito original de esta obra, guardado en la Real Academia de la Historia de Madrid, contiene ilustraciones originales, otras del llamado «Compendio anónimo» y de la Historia de Alonso de Ovalle. La edición de 1889 —obtenida desde una copia del manuscrito original- no incluye ninguna de estas ilustraciones, lo que en cierta medida reduce su valor. De los once libros en que se divide la Historia, los cinco primeros están dedicados a la historia natural. El libro sexto se refiere a los indígenas de Chile, especialmente de los mapuches. Los libros que van del séptimo al décimo están consagrados a la denominada Guerra de Arauco. El último libro de la obra, el undécimo, se dedica al estudio de la sociedad chilena urbana, particularmente de la elite criolla.

Desde su publicación la obra de Vidaurre no ha tenido una buena acogida por parte de los críticos, ni mucho menos una dedicada atención. Entre lo más importante que se escribió respecto a la obra del jesuita a fines del siglo XIX, podemos destacar lo realizado por José Toribio Medina, que además del trabajo introductorio para la edición de la $\mathrm{CHCH}$, que ya hemos mencionado y en el que no le resta todo mérito, algunos años antes le había dedicado algunos pequeños fragmentos en su Historia de la literatura colonial de Chile. ${ }^{22}$ Más tarde, en 1891, el historiador español de la Compañía de Jesús Francisco Enrich se referiría al expulso en su libro dedicado a la orden ignaciana en Chile, entregando datos bibliográficos poco precisos y refiriéndose con algunos reparos a su Historia. ${ }^{23}$ Pero sería Diego Barros Arana, una autoridad en la historiografía chilena, el que proferiría las críticas más duras en contra de la obra del jesuita. En su Historia jeneral de Chile (1884-1902), Barros Arana señala que Vidaurre no estaba preparado para escribir el libro que se propuso, por no disponer de los materiales necesarios y por carecer del talento y la educación para realizar aquel trabajo. Para el historiador decimonónico, en la obra del jesuita, que — cabe mencionar - revisa desde el manuscrito copiado en España, no encuentra nada que revele un espíritu sagaz y penetrante, sino todo lo contrario, considera que su estilo es mediocre, su mirada superficial, su vocabulario deficiente y con frecuencia impropio y no le habría servido de nada escribir su Historia en un contexto más ilustrado como era el europeo, por lo que «ni la historia ni la literatura ganarían gran cosa con su publicación» pues su estudio y análisis no permite obtener ningún dato importante. ${ }^{24}$

22 Medina, 1878, II, 420-424.

23 Enrich, 1891, II, 450-451.

24 Barros Arana, 1884-1902, VII, 543-544. 
El primer crítico que se estudió exclusivamente algunas particularidades de la obra de Vidaurre fue Eduardo Solar Correa en un trabajo de su libro Semblanzas literarias de la Colonia (1933) titulado «Felipe Gómez de Vidaurre, 1748-1818». Aparte de breves reseñas de su vida y obra presentes en algunos libros y artículos de prensa (principalmente de Concepción), más la valiosa, pero poco aprovechada, información que se encuentra desperdigada en los trabajos del historiador jesuita chileno Walter Hanisch Espíndola, lo último importante acerca de la obra del jesuita es un artículo de Fernando Casanueva (2001) y un trabajo de Luis Hachim Lara publicado en $2013 .^{25}$

Es probable que la exagerada indisposición de Diego Barros Arana haya influido en el poco entusiasmo que por la obra del expulso tuvieron los especialistas contemporáneos a este historiador y esto a su vez pudo propiciar el desconocimiento de los críticos que vinieron más tarde. Si bien, nuestra intención no es hacer una defensa en el plano de lo estético de la obra del jesuita, consideramos que contiene varias particularidades que son muy interesantes y que han pasado casi inadvertidas, como por ejemplo, ciertas descripciones que hace de la sociedad mapuche y de los criollos, así como también las sugerencias y propuestas para mejorar la educación, la agricultura y el comercio del Reino de Chile, que por lo demás objetan el juicio de Barros Arana, pues se ajustan perfectamente, como veremos más adelante, al pensamiento ilustrado del siglo XVIII.

\section{El nuevo concepto de Historia}

Como se dijo más arriba, probablemente el primer estudio que fija la atención en ciertas características originales de la obra de Vidaurre es el de Eduardo Solar Correa. En este ensayo el crítico literario chileno señala que si bien en la obra del jesuita no se obtendrán detalladas noticias de batallas y escaramuzas, ni una depurada y preciosa narración, contiene pasajes que aportarían a las letras chilenas «un nuevo concepto de historia». Para Solar Correa esta nueva forma de comprender la narración histórica en la obra de Vidaurre se percibe cuando comienzan a tomar relevancia en la narración los aspectos de la vida cotidiana chilena, lo que lo aproximaría a un espíritu dieciochesco, más acorde con la época. Solar Correa incluso se pregunta si

25 Insistimos que las referencias presentadas son hasta la fecha los únicos trabajos impresos que hemos ubicado que presenten alguna importancia para el estudio de la obra de Vidaurre. 
Vidaurre habrá conocido las novísimas teorías de Voltaire sobre la manera de escribir la Historia, a lo que se responde que «posiblemente». ${ }^{26}$

Otra característica presente en el libro de Vidaurre que Solar Correa establece como ejemplo de esa evolución en las letras nacionales es su crítica hacia la mayoría de las obras anteriores dedicadas al Reino de Chile por tratarse casi únicamente de la Guerra de Arauco. El jesuita señala que estas obras, en las que seguramente incluía algunas de sus colegas, «no presentan más que un campo, todo él bañado de sangre y cubiertos de cadáveres; no hacen más sino mutuas hostilidades [...] ¿Pero qué provecho saca el público? No otro que el impresionarse contra aquella parte que ve pintada más cruel, más inhumana». ${ }^{27}$

A pesar de lo que sostiene, Vidaurre no pudo abstenerse de relatar las noticias del interminable enfrentamiento entre mapuches y españoles, por la simple razón de que aquellos sucesos constituyen la base de la sociedad colonial chilena. A esto dedica cuatro partes de las once que conforman su libro, siendo además las más extensas. La escasez de materiales bibliográficos relacionados directamente con el Reino de Chile fue un inconveniente para el autor a la hora de enfrentar estos pasajes históricos, ya que por más que en sus primeros años en Imola estuviera rodeado por un grupo de más de doscientos chilenos ${ }^{28}$ que bien pudieron aportarle algunas noticias del país, los libros que trataban de Chile con los que contaba — además de los textos de viajeros europeos- eran casi únicamente la obra de Alonso de Ovalle, La araucana de Alonso de Ercilla, un manuscrito de la Historia general del reino de Chile de Diego de Rosales y otro de Miguel de Olivares. ${ }^{29}$ Este último, con el cual compartió esos primeros años de exilio, fue el que más aportó a la parte dedicada a la historia civil, cuestión que puede ser comprobada incluso desde algunos errores presentes en la obra del expulso, en los que parece seguir el manuscrito de Olivares, como cuando confunde a Francisco de Aguirre con Francisco de Villagra como el militar

26 Solar Correa, 1969, 194-196.

27 Vidaurre, 1889, I, 4.

28 Hanisch, 1972, 229.

29 Se trata del manuscrito de Historia militar, civil y sagrada del Reino de Chile, cuya primera y única edición apareció en 1864 en la $\mathrm{CHCH}$. La parte publicada fue escrita por Miguel de Olivares unos años antes de la expulsión de la Orden. El jesuita reclamó desde el exilio a las autoridades españolas la segunda parte de esta Historia, requisada en Lima y supuestamente bastante avanzada. Esa segunda parte de la obra de Olivares jamás apareció y los fragmentos que encontró Medina en Lima y que publicó en 1901 en la $\mathrm{CHCH}$ como parte de esa obra extraviada, a nuestro juicio no son de la autoría de Olivares. 
enviado por el gobernador Pedro de Valdivia a explorar la zona de Cuyo, ${ }^{30}$ dato equivocado que también toma Juan Ignacio Molina en su Saggio sulla storia civile del Chili (1787).

A pesar de esta utilización, la Historia de Vidaurre está lejos de ser un compendio de la obra de Olivares, como le imputa Diego Barros Arana. ${ }^{31}$ $\mathrm{Si}$ bien es cierto que contiene muchas informaciones del manuscrito de su colega, estas son reinterpretadas y no siempre llega a las mismas conclusiones. Por ejemplo, es factible que una información como el disgusto de los pehuenches por la fundación en sus tierras de San Bartolomé de Chillán haya sido obtenida de la Historia de Olivares, pero mientras este señala que gobernador Alonso Sotomayor, al enterarse que los indígenas del lugar estaban invadiendo la nueva ciudad, mandó dos compañías pagadas y bien armadas a desalojar a los intrusos, lo que hicieron supuestamente sin mayores inconvenientes, ${ }^{32}$ Vidaurre señala, cuestión que no dice o no advierte Barros Arana, que estas dos compañías fueron a Chillán solo a saquear las haciendas de los pobladores y en el momento en que el gobernador se hizo presente, escaparon a los montes con el ganado que habían robado. ${ }^{33}$

Si bien Vidaurre no cita ni menciona a Miguel de Olivares en estos pasajes para discutirle, podemos aseverar que esta utilización crítica de las fuentes se ajusta a esa fuerte «posición en favor de la verdad» que, según el historiador alemán Reinhart Koselleck, en los historiadores del último tercio del siglo XVIII se allanó a través de la Ilustración. ${ }^{34}$ En esta misma línea debemos ubicar los juicios críticos expresados al inhumano proceder en batalla de algunos gobernadores de Chile, como el recién señalado Alonso Sotomayor, pero principalmente de García Hurtado de Mendoza y Manrique, que difieren de manera considerable del retrato que Miguel de Olivares hace del joven gobernador que reemplazó a Pedro de Valdivia. ${ }^{35}$

\section{Los mapuches}

Sin desconocer que la nueva interpretación de algunos hechos históricos que hace el jesuita en su obra es importante de distinguir, lo más

30 Vidaurre, 1889, I, 103.

31 Barros Arana, 1884-1902, VII, 542.

32 Olivares, 1864, 238.

33 Vidaurre, 1889, II, 153.

34 Koselleck, 2004, 61.

35 Vidaurre, 1889, II, 107, 153. 
sobresaliente —o si se quiere novedoso— a nuestro juicio son las descripciones que hace de los mapuches y de la sociedad criolla, que ocupan los últimos capítulos de cada volumen de la edición de 1889. Respecto a los indígenas de Chile, ya en el prefacio Vidaurre se quejaba del poco estudio que los autores anteriores les habían dedicado, críticas que dirige a escritores como Alonso de Ercilla y Pedro de Córdoba y Figueroa, pero también a sus colegas jesuitas Alonso de Ovalle y Diego de Rosales:

Como que no condujese a la mejor inteligencia de su historia, ni el mundo en ello se interesase, se han pasado sin decirnos ni la construcción de la máquina animal de sus primitivos habitantes, sobre [lo] que hay en Europa no pocos errores que desvanecer, sin indicarnos los datos de sus ánimos, que se caracterizan del todo bárbaros, del todo inhumanos por el común de los europeos, sin dar una ligera idea de su lengua, que no se estima, porque no se ha hecho conocer; sin explicarnos su religión, por lo que falsamente son tenidos por ateístas; sin decir sus costumbres, que por eso son tenidos por desarreglados al exceso; sin deslindar su gobierno doméstico, civil y militar, porque se ha creído reinar entre ellos una perfecta anarquía, un enorme desbarato y un desordenado y tumultuante ejercicio de las armas. ${ }^{36}$

Para el expulso un mayor conocimiento de los indígenas hubiese ayudado a alcanzar uno de los propósitos más importantes de la conquista: « ¿Cuán útil pues hubiera sido una historia que hiciese conocer a fondo estos indios! ¡Cuántos más vasallos tuviera hoy S. Mag.! ¡Cuánto más floreciente estuviera hoy la cristiandad entre ellos!». ${ }^{37}$

Las descripciones acerca de la cultura mapuche en la Historia geográfica, natural y civil del Reino de Chile generalmente se ubican en un plano de respeto, incluso cuando se refiere a algunos ritos que considera poco creíbles, como la ceremonia de sanación machitun, no los define con calificativos injuriosos como «patrañas» 0 «prácticas diabólicas», tan frecuentes en las obras anteriores. ${ }^{38}$ Asimismo, cuando destaca el amor por la libertad y por lo que creen digno, tal como el coraje, la ciencia militar, la perseverancia en las fatigas, la hospitalidad en sus casas, el cumplimiento de sus contratos, etc., así como la constancia por infundir toda esta suma de virtudes en sus hijos, se alcanza a percibir una imagen positiva de los mapuches, que se acentúa cuando señala que esas son costumbres que los «cristianos» deberían imitar. ${ }^{39}$

36 Ibidem, 4.

37 Ibidem, 5.

38 Ibidem, 318-322.

39 Ibidem, 309. 
Vidaurre defiende estas apreciaciones y juicios acerca de los mapuches señalando que él no tiene predilección por estos, sino que al contrario, tiene sobrados motivos para desdeñarlos, pues considera que son pocas las familias que han derramado tanta sangre en la Guerra de Arauco como la suya. Pese a esto, lo que lo incita a señalar estas características de los indígenas de Chile sería «el amor a la verdad [...] y no la ciega pasión, con que han escrito hasta ahora los autores», que leídos con cierto cuidado, podrá notarse que se contradicen cuando se refieren al indígena como un ser sin mayores capacidades, pero al tratar de la guerra, y en sus afanes por sobrevalorar las aptitudes de los españoles, lo enaltecen, señalando por ejemplo, la buena disposición de sus tropas o su ordenada disciplina militar. ${ }^{40}$

Son muy interesantes también algunas reflexiones que el jesuita hace de otros aspectos culturales de los mapuches, como objetar la idea de ser «hombres sin religión» solo «por la manera libre de vivir y el no ver en ellos sacerdotes, sacrificios ni lugares sagrados», sin concebir que pudieran tener una religiosidad que se acomodara a su forma de pensar y vivir, ${ }^{41} \mathrm{o}$ por ser «sumamente amantes de la libertad» no posean un código de leyes (admapu) que regule su comportamiento y castigue delitos como «la traición, el homicidio, el adulterio, el hurto y el maleficio». ${ }^{42}$ En este mismo orden ubicamos la descripción de sus narraciones orales (o fábulas, como las define el jesuita), que van transmitiendo generacionalmente y la utilidad que prestaban - y que continúan haciéndolo-, como el antiguo relato de un intenso temblor y posterior maremoto que cubrió gran parte de la tierra, que instituyó en los mapuches la costumbre de subir a los «tentenes» (cerros que terminan en tres puntas y únicos montes que el mar no alcanzó a cubrir aquella vez), inmediatamente después de un sismo proveídos de agua y alimentos para varios días. ${ }^{43}$

Pero la que parece resaltar entre estas observaciones es la desprejuiciada explicación que el jesuita ofrece acerca de la poligamia de los mapuches, uno de los obstáculos más importantes para los misioneros a la hora de introducir a los indígenas en el evangelio. Vidaurre consideraba que «la incontinencia por la pluralidad de las mujeres» no era un vicio predominante que se pueda contar entre los mapuches; según el jesuita, esta práctica se explica más por el provecho económico que acarrea, que por satisfacer

40 Ibidem, 309-310.

41 Ibidem, 317.

42 Ibidem, 323-326.

43 Ibidem, 322. 
apetitos sexuales, «cuantas más mujeres tienen, son, en realidad, más ricos». ${ }^{44}$ Para Fernando Casanueva el expulso presenta aquí argumentos antropológicos adelantados para finales del XVIII. ${ }^{45}$

Si bien coincidimos con Casanueva, es preciso señalar que esta idea de Vidaurre pudo ir desarrollándose desde muy temprano entre los jesuitas de Chile, pues, como señala Rolf Foerster, cuando los padres jesuitas comprendieron que la poligamia sería una práctica muy difícil de eliminar entre los mapuches, optaron por una solución que dejaba algo más conforme a ambas partes; Foerster cita una carta annua del 17 de mayo de 1609 en la que el padre Horacio Vecchi, encargado de las misiones de Arauco, le explica al superior Diego de Torres en qué consistía esta solución:

El mayor impedimento que tienen nuestros indios para recibir nuestra santa fe, es el entender que se les han de quitar sus mujeres; mas cuando entienden que si se hacen cristianos se han de casar con una y de las demás se pueden servir para hacer sus chacras y lo demás que han de menester, no se les hace tan dificultoso. ${ }^{46}$

Sin embargo, no todas son buenas apreciaciones para los indígenas de Chile en la obra de Vidaurre, también manifiesta varios de los prejuicios que se vienen arrastrando desde mediados del siglo XVI y que hasta hoy pueden percibirse en parte de la sociedad chilena, en buena medida por la influencia que ejerce el discurso discriminatorio y racista de un sector importante de los medios de comunicación. Por ejemplo, los critica por la alta mortalidad infantil que provocaba el exagerado consumo del alcohol que compraban a los españoles (destilados, como el aguardiente) o de la chicha que elaboraban ellos mismos. La indiferencia del hombre por el trabajo, es otra de las

44 Ibidem, I, 310. Más adelante, al final del capítulo titulado «Gobierno civil de los chilenos», explica más detalladamente cómo se producen y en qué consisten estos enlaces. Ibidem, 326.

45 Casanueva, 2001, 227.

46 Foerster, 1996, 158-159. Julio Retamal Ávila señala que en un padrón levantado por las autoridades españolas de una comunidad indígena de la zona de Arauco y controlada por los jesuitas se puede detectar cómo se presenta la ancestral práctica de la poligamia, pues si bien en una lectura superficial de los registros lineales se observan solo matrimonios monógamos, haciendo un análisis más detenido se comprueba «que los hijos de un mismo padre tenidos en distintas madres se disfrazan en una familia uniparital». Sostiene también que esta práctica «casi imposible de erradicar» no fue un obstáculo importante ni siquiera para las instancias de los parlamentos de paz, aunque en estos participaran las más altas autoridades eclesiásticas, por ejemplo, una de las cláusulas que incluyó el gobernador Tomás Marín González de Poveda en el Parlamento de Yumbel del 16 de diciembre de 1692 — que permitía la instalación de misiones religiosas - consistía en el abandono de «la pluralidad de mujeres», sin embargo, ante la negativa de los indígenas, por constituir la base de su economía, Marín de Poveda tuvo que acceder a que pudieran casarse con una mujer y tener las otras como criadas. Para Retamal esta indicación permitió replicar entre los indígenas lo que ocurría en la sociedad española: la práctica del adulterio. Retamal, 2005, 62. 
costumbres de los indígenas que reprocha; según el jesuita, los hombres mapuches creen que nacieron solo para la guerra, despreciando cualquier otra actividad que no tenga que ver con la milicia y ni siquiera se inquietan cuando sus mujeres se hacen cargo de oficios más pesados, como el trabajo de la tierra, el cuidado de los animales, el abastecimiento de leña, etc. ${ }^{47}$

Probablemente en la misma línea de lo anterior podemos ubicar la aprobación que Vidaurre hace de la encomienda indígena. Este parecer, que podría ser considerado polémico para un jesuita, no hace más que manifestar aquella disparidad de criterios que tuvieron en relación a este tema algunos jesuitas criollos, la mayoría descendientes de familias encomenderas, frente a una parte de sus colegas europeos, principalmente españoles, como Luis de Valdivia y Diego de Rosales. El expulso sostiene que si la encomienda hubiese sido siempre llevada de forma humanitaria, no habría que estar en contra de esa «bellísima» institución..$^{48}$ Este calificativo, tan contrario al pensamiento del recién mencionado Luis de Valdivia, para quien la encomienda no era sino la esclavitud de los indígenas y, al mismo tiempo, uno de los obstáculos más importantes para la evangelización ${ }^{49}$ se atenúa en cierta manera con el recuerdo de un encomendero de Concepción que habría dado un trato digno a sus indígenas, al preocuparse de que pudieran asistir diariamente a la iglesia para rezar el catecismo, además de vestirlos con regularidad, curar su enfermedades y ofrecerles tierras para criar animales y sembrar. Señala que si otros «feudo-encomenderos» hubiesen procedido así con los indígenas, estos no habrían disminuido tanto. ${ }^{50}$

\section{Los criollos chilenos de finales del siglo XVIII}

Si bien el «Libro último» de la Historia de Vidaurre, titulado — sugestivamente a nuestro juicio- «Estado presente del dominio español en Chile», comienza describiendo las castas existentes en el país, donde se pueden leer elogiosas palabras y singulares reflexiones acerca de los mestizos, por lo menos para los textos del periodo colonial chileno, que «sacan todo lo bueno de ambas naciones», ${ }^{51}$ los capítulos están dedicados

47 Vidaurre, 1889, I, 342-347.

48 Ibidem, 299.

49 Memorial del padre Luis de Valdivia a S.M. sobre la importancia de cortar la guerra de Chile, 1610, en Medina, José Toribio (ed.), Biblioteca hispano chilena (1523-1817), Santiago de Chile, Fondo Histórico y Bibliográfico José Toribio Medina, 1963, II, 60-93, especialmente p. 80.

50 Vidaurre, 1889, I, 299.

51 Ibidem, II, 283. 
casi exclusivamente a los criollos, su clase social. Se puede percibir que el jesuita se siente muy a gusto narrando una serie de datos curiosos de la acomodada sociedad chilena de finales del siglo XVIII, como la dedicación que ponían los hombres en adornar sus caballos («la silla es toda cubierta de terciopelo bordado de oro y plata»), los sacrificios de las mujeres por conseguir el ideal de belleza de la época, como era tener pies pequeños, o los detalles de los diferentes trajes y del lujoso mobiliario, ${ }^{52}$ todas observaciones que para un historiador como Barros Arana solo podían emanar de un observador superficial y desprovisto de rigurosidad estadística. ${ }^{53}$

Una de las preocupaciones evidentes de Vidaurre respecto a la aristocracia chilena era la vinculación que algunos de sus miembros estaban sosteniendo por esos años con sujetos que provenían de la península y que, según las informaciones que obtuvo cuando pasó por España, descenderían de una reconocida baja extracción social. Sostiene que estos enlaces ponen en riesgo la conservación de la nobleza chilena, como también, podían ser motivo de desprestigio en España. ${ }^{54}$ Probablemente estos sujetos de «poca nobleza» que el jesuita despreciaba, no eran otros que los nuevos burócratas y comerciantes que desde mediados del siglo XVIII comenzaban a llegar por oleadas a los territorios americanos, siendo además preferidos en la alta administración colonial por las autoridades borbónicas, en un esfuerzo de la Corona, según John Lynch, por «desamericanizar» el gobierno de América y controlar a los criollos, periodo que habría comenzado en 1765 y que el historiador inglés ha denominado como la «segunda conquista de América». ${ }^{55}$

Por este temor, que parece responder más a la tradición que a un espíritu ilustrado, aconseja a los padres que antes de casar a sus hijas por lo menos comprueben los datos del recién llegado a América. Esto lo dice sin ocultar su preferencia por los europeos para tales enlaces, ya que, según su propia experiencia y a riesgo de ser tomado a mal por algunos habitantes de Chile, vinculándose con gente del viejo continente, se podían mantener relaciones directas con Europa y con España, lugares donde es «preciso recurrir para cualquier pretensión». Por otro lado, la preferencia por el europeo se debía a que estos no dilapidaban el dinero como lo hacían los chilenos. ${ }^{56}$

52 Ibidem, 303-308.

53 Barros Arana, 1884-1902, VII, 543.

54 Vidaurre, 1889, II, 286.

55 Lynch, 2010, 28. La primera conquista, dice Lynch, habría sido para controlar a los indígenas.

56 Vidaurre, 1889, II, 286. 
Vidaurre señala que en Chile existen familias muy distinguidas, como «los Carreras, los Girones, los Solares, los Covarrubias, los Prados», etc., y otras menos nobles que estarán «escondidas en los rincones del Reino y en sus campañas, gozando de los bienes de fortuna en que los ha puesto el desbarato de sus antepasados». También dice que hay algunas familias de la nobleza chilena que gozan de importantes y medianas fortunas, pero que no alcanzan los «caudales de tan desmesurada grandeza» que existen en México y Perú. Según el jesuita esto no se debería a la inferioridad de riquezas del Reino de Chile, sino al precario comercio que se practica y a la continua guerra con los indígenas que ha retrasado el progreso y el aumento de la población. ${ }^{57}$

Los criollos chilenos también serían responsables de la inferioridad económica del Reino de Chile, pues, más allá de alabar los ánimos de los jóvenes chilenos, insta a los padres a crear conciencia en sus hijos varones del valor de lo material, porque el criollo «nacido en abundancia, criado con magnificencia, alimentado con regalo, contentado en un todo de estas cosas, se cría sin apego al dinero, se acostumbra a la ostentación, de donde viene el lujo y la poca aplicación a buscar dinero». Vidaurre señala —al parecer con cierta experiencia - que a pesar de que los padres chilenos son conscientes de que en esto hacen mal, consideran equivocadamente que ese defecto de los jóvenes se corregirá cuando lleguen a la madurez. ${ }^{58}$

De las mujeres criollas chilenas, «generalmente bellas, de buen talle y proporcionado a su sexo, su color blanco rosado y su pelo largo, rubio y sutil», sostiene que la gran preocupación de los padres es convertirlas en buenas amas de casa, porque según la tradición chilena «la mujer gobierna el gasto de toda la casa y el marido atiende o al comercio o al empleo que goza en la ciudad». Por eso cuando se casan, generalmente muy jóvenes, saben todo lo relativo al manejo doméstico. Esta experiencia, que también consiste en manejar el caballo y estar al tanto de las cosechas, les ayuda mucho si se quedan viudas y con hijos pequeños, pues al conocer todo lo que proviene de la hacienda «no las pueden engañar los mayordomos». Para Vidaurre la autonomía que logra la mujer criolla respecto a su marido produce más beneficios que problemas al matrimonio, pues esta experiencia les permite convivir en mayor armonía con sus maridos, lo cual se comprueba en los pocos divorcios que se presentan en Chile. ${ }^{59}$

57 Ibidem, 287.

58 Ibidem, 290-292.

59 Ibidem, 297-298. 
Sin embargo, las criollas chilenas no se libran de la ostentación - evidente, al parecer, entre los miembros de clase alta chilena de aquella época-, manifestada fundamentalmente en el lujo de sus vestidos, que muchas veces compran sin necesidad o porque ha pasado de moda el último modelo que adquirieron. Esta actitud, según el expulso, pone muchas veces en juego la economía familiar, ya que sus propios maridos, «amigos de parecer bien», en el afán de satisfacer los caprichos de sus mujeres derrochan grandes cantidades de dinero. ${ }^{60}$

\section{Las propuestas del jesuita}

El sentido crítico que muestra Vidaurre con ciertas costumbres de la sociedad criolla chilena y de los mapuches, no se percibe a la hora de referirse a la administración colonial. Es justo señalar, eso sí, que críticas en ese sentido eran casi imposibles de realizar por el jesuita, pues aparte de arriesgar la pensión, podía hipotecar cualquier posibilidad de regreso a América, seguramente uno de sus más grandes anhelos, como para la gran mayoría de los jesuitas expulsos americanos. Lo que sí es posible observar son sugerencias encaminadas a reestructurar algunos ámbitos de la sociedad chilena para su mejor funcionamiento, que por lo demás, no deja de ser una forma efectiva de criticar. Entre los más importantes consejos, encontramos propuestas en áreas como la educación de los criollos, la agricultura y el comercio. Acerca de la enseñanza de las ciencias, el jesuita dice estar completamente seguro que los criollos chilenos tendrían grandes avances si se hicieran cambios al existente modelo escolástico, comenzando, por ejemplo, por complementar la enseñanza del latín —en el que se emplean muchos años y con escasos resultados positivos- con conocimientos en retórica, poesía, geografía y geometría, para que de esa forma pueda ser una herramienta útil en la comprensión de la filosofía, y que esta ya no sea «de la abstracta y metafísica». Estaría sugiriendo el estudio del sistema cartesiano, como también el newtoniano, métodos — dice- que ya estarían siendo utilizados por algunos de sus compatriotas en el Reino de Chile. ${ }^{61}$

En cuanto a la agricultura sus ideas están muy cercanas a los planteamientos fisiócratas del XVIII, que consideraban esta actividad como la

60 Ibidem, 298

61 Ibidem, 294. Estas propuestas de cambios en la enseñanza Vidaurre las hace con cierta experiencia, recordemos que el jesuita se desempeñaba como profesor en el colegio de la Compañía en Santiago. 
única capaz de generar riquezas para una nación; el jesuita piensa que la agricultura, y no la explotación de las minas, debería ser la primera actividad productiva para los chilenos, ya que de ella depende el progreso de las ciudades. Piensa también que Chile es el lugar ideal para fundar una escuela agrícola que perfeccione este arte, como lo considera, el cual, si bien se practica con frecuencia y generalmente de buena forma, pues casi no existe campiña en Chile que no esté sembrada, lo cierto es que el éxito de esta práctica se debe más a la riqueza de la tierra que al conocimiento del labrador. La escuela agrícola también ayudaría al mayor desarrollo de otras actividades que se dan en las haciendas, como las curtiembres y la elaboración de productos lácteos. Agrega también que los maestros o personas aptas para capacitar en diferentes áreas de la producción lograrían excelentes avances con los chilenos, pues a diferencia de lo que se cree, son muy trabajadores y «se muestran deseosos de saber». ${ }^{62}$

Es importante señalar que la familiaridad de Vidaurre con el fisiocratismo seguramente se deba a su obra Conversaciones familiares de un Padre americano con sus hijos Caupolicán y Colocolo que, según Hanisch, sería una adaptación de «El gentil hombre agricultor, escrita en italiano y que le sirve de base a sus disquisiciones». Esta obra, hasta hoy inédita, que el jesuita debió comenzar después de redactar la Historia geográfica, natural y civil del Reino de Chile (es decir, con posterioridad a 1782) ) $^{63}$ y en la que aun estaba trabajando cuando se le solicitó su Historia, está dividida en nueve partes, «la primera trata de la crianza física, civil y moral de los hijos; de la segunda a la sexta, de la agricultura, la séptima de la cría y multiplicación del ganado, la octava de las fábricas, caseríos, etc., y la novena del cultivo del lino y del cáñamo». ${ }^{64} \mathrm{Se}$ sabe que Vidaurre dio noticias de su trabajo por una carta que el 23 de agosto de 1788 envía Luis Gnecco a José Nicolás de Azara, embajador de España en Roma, en la que le comenta que el ex jesuita necesita tres meses para arreglar su Historia y también «me pide dirija a V.S. el otro papel, también adjunto, que contiene el prospecto de otra obra, que está trabajando, para que si fuera de su agrado se sirva enviarla al Señor don Antonio Porlier». ${ }^{65}$ Alcanzó a enviar cuatro tomos

62 Ibidem, 299-300.

63 Vidaurre le informa a Juan Nicolás de Azara el 16 de mayo de 1785 que está traduciendo «El gentil hombre agricultor» (Hanisch, 1972, 228), así que es probable que después de finalizar este trabajo comenzara a redactar Conversaciones familiares de un Padre americano con sus hijos Caupolicán y Colocolo.

64 Hanisch, 1972, 230.

65 Ronan y Hanisch, 1979, 43. 
a la corte para su aprobación y publicación, ${ }^{66}$ que serían los manuscritos originales que se guardan en los fondos de la Real Biblioteca de Madrid.

En relación al comercio, Vidaurre sugiere sus propuestas más atrevidas al hacerse vocero de una de las mayores preocupaciones de la elite criolla de finales del siglo XVIII, a saber, la imposibilidad de desarrollar sus negocios debido al monopolio comercial ejercido desde un primer momento por la Corona. Consideraba que Chile debía balancear la asimétrica relación comercial que mantenía con «la Europa» (se refiere solo a España), en la que desempeñaba el papel pasivo, pagando altas sumas de dinero por una variedad de productos — que iban desde los paños de cocina, hasta el fierro y sus derivados - que en Chile no se elaboraban. Esa situación podía mejorar desde su perspectiva, incluso sin la instalación de industrias locales que fabricaran parte de esos productos, sino solo enviando a España y al resto de los países europeos la materia prima que en Chile abundaba y que en el viejo continente hacía falta, como el trigo, el cáñamo, el cuero, etc. ${ }^{67}$ Esta propuesta, la de exportar los recursos naturales, no era otra cosa que la apertura de los mercados europeos para los productos chilenos y debía implementarse aprovechando la gran cantidad de puertos que tiene el país, así como los ríos y canales que hacen comunicable en un corto tiempo gran parte del territorio con la costa. ${ }^{68}$

Quizás estas reflexiones y consejos tan alejados de la política económica exigida por la administración de los Borbones e implementada para optimizar las riquezas provenientes de sus colonias americanas y minimizar el contrabando, que como concesión más importante solo permitió a los empresarios criollos un mayor comercio entre los puertos hispanoamericanos con los de España, pero nunca la posibilidad de comerciar con otros mercados europeos, fueran las responsables de que esta obra no se publicara en su momento. Al parecer, no existen datos que den cuenta de si hubo misivas entre el expulso y el ministro Porlier por algo relacionado con algún cambio o corrección de la obra que envió en enero de 1789.

\section{Mártir de la independencia de Chile}

Como apuntamos en una nota al comienzo de este trabajo, quisiéramos presentar y relacionar algunos datos del jesuita que no se han difundido

66 Hanisch, 1972, 230.

67 Vidaurre, 1889, II, 313-314.

68 Ibidem, 314. 
mayormente y menos de forma conjunta, pero que pueden ayudar a construir una biografía más completa de este escritor chileno, particularmente de sus últimos veinticinco años, que coinciden con los tiempos de la emancipación americana, años además en los que el expulso parece haber madurado algunas ideas independentistas que esboza en su obra, ya que al parecer habría tenido una significativa — como también lastimosa - participación en la lucha por la independencia de Chile, particularmente en su natal Concepción.

Vidaurre vivió en Bolonia hasta 1785, después lo haría en Sinigaglia. ${ }^{69}$ A fines de 1789 acompañó a Juan Ignacio Molina a Roma en un breve viaje del abate que, entre otros fines académicos, buscaba ampliar sus relaciones con otros científicos jesuitas, como Felipe Luis Gilij y Javier Xuárez. ${ }^{70}$ No sabemos si Vidaurre permaneció por más tiempo en Roma ${ }^{71}$ o si regresó más adelante, pero desde esta ciudad en 1793 hace algunos trámites para conseguir una doble pensión; primero le escribe a Juan Acedo-Rico, secretario de Gracia y Justicia y posteriormente al embajador José Nicolás de Azara, para que puedan interceder en su favor. En la carta a Acedo-Rico - mencionada en una nota anterior - Vidaurre se queja del lamentable estado en que se encontraba, «sin apoyo alguno en la corte, abandonado del todo de los suyos y extremadamente necesitado, y ya molestado de diversos achaques, particularmente de la vista, que le va faltando». Como principal mérito para obtener el beneficio dice ser el autor de la obra anónima Compendio de historia natural, geográfica y civil del Reino de Chile. ${ }^{72} \mathrm{Si}$ bien la carta al embajador Azara tiene un tono similar a la de Acedo-Rico, al ser más extensa y algo más cuidada en su redacción es más reveladora del estado de ánimo de Vidaurre. La presentamos íntegra, pues consideramos que es un documento que puede representar el abandono en que se encontraban muchos jesuitas expulsos americanos en su exilio europeo a finales del siglo XVIII.

Excmo. Señor: No llegaría a tocar las puertas de V. Excia., si no supiera que ellas están abiertas siempre para todos; no lo obligaría a interrumpir los gravísimos negocios a que asiste y preside, si no estuviese cierto que V. Excia. reputa, por su piedad, por el mayor negocio de los que están a su cargo el dar oídos al afligido y alivio al necesitado. El que se presenta a Excia. es un sacerdote destituido de todo apoyo, abandonado del todo de los suyos, extremadamente necesitado y ya molestado de varios achaques,

69 Tampe, 2008, 269.

70 Ronan y Hanisch, 1979, 51.

71 Según Tampe habría vivido algunos años en Roma.

72 Hanisch, 1976, 175. 
particularmente de la vista, que a largos pasos va perdiendo. El impelido de la miseria, en la que se halla, llega con estos motivos a tocar las puertas del piadoso corazón de $\mathrm{V}$. Excia., llevando en las manos un parto de sus limitados talentos, que pasa a V. Excia. en ese ejemplar, que le remite, para suplicarle que por premio de sus fatigas le obtenga de Su Majestad segunda pensión para remedio de sus graves necesidades, y, si no es de este modo, irremediables; porque no tiene que esperar cosa alguna de sus parientes. La obra es anónima, pero en el instrumento que incluye al Excmo. Señor Secretario de Gracia y Justicia, hace constar ser él su autor. En V. Excia. espera, en V. Excia. confía, y entre tanto le llega el despacho favorable, queda rogando a Dios por la prosperidad de V. Excia. Roma, 28 de Agosto de 1793.

Besa la mano de V. Excia. su más rendido servidor y Capellán D. Felipe Gómez de Vidaurre. ${ }^{73}$

Este trámite no prosperó porque Vidaurre no apuntó el título de la obra en la carta recién citada y también porque Juan Acedo-Rico no adjuntó el documento que avalaba la autoría de Vidaurre en su presentación al embajador. Azara informa que el archivo no encuentra una obra que se ajuste a lo que se dice en la carta, que puede ser uno de los muchos manuscritos anónimos que existen allí, pero que sin el nombre de la obra no puede hacer nada. Al parecer, Acedo-Rico no respondió al embajador y también es probable que Vidaurre no se haya enterado de esta dificultad tan fácil de solucionar. Esta nueva decepción, que se venía a sumar al silencio de la corte respecto a los trabajos que ya había mandado, pudo desmotivar definitivamente la relación del jesuita con sus escritos, por lo menos no existen datos de que haya realizado algún intento más por publicar sus trabajos, ni de haber comenzado a redactar otros, ni siquiera en los años de relativa tranquilidad que vivió en Chile.

La suerte para Vidaurre parece mejorar algunos años después, por lo menos en apariencia, ya que para 1797 se encontraba en Barcelona a la espera de la promulgación de la cédula de Carlos IV que permitiría a los ex jesuitas españoles y a los que pertenecían a las colonias de España regresar a sus lugares de origen. Esta cédula fue expedida en el mes de enero de 1798. Ese mismo año, Vidaurre junto a su primo H. Pedro Arduz —un ex jesuita de la provincia de Paraguay que se había casado en el exilio- y dos hijos de este, se embarcaron rumbo a Buenos Aires. De esto se tiene noticia porque escribieron desde Barcelona solicitando auspicio para este viaje. Además de este dinero, que debía entregarse en Málaga porque de ahí partían, también un poco más para continuar el viaje por tierra desde Buenos

73 Ibidem, 176. Según Hanisch esta carta y también la que envía al secretario de Gracia Justicia se encuentran en el Archivo del Ministerio de Asuntos Exteriores de Madrid. 
Aires. Se les concedió mil reales y se les notificó que obtengan pasaporte e informen su residencia para enviarles la pensión. ${ }^{74}$

Las próximas noticias de Vidaurre se tienen dos meses después y son alarmantes; escribe desde Málaga pidiendo auxilio, ya que habían sido capturados por un pirata a poco de zarpar. Dice:

Hemos sido prisioneros de un pirata inglés, el cual nos ha botado a tierra desnudos, quitándonos hasta la pobre ropilla de los dos niños. Hemos llegado a esta ciudad pasando trabajos cuasiincreibles [sic], pidiendo limosna a este y aquel, y aunque hemos hallado piedad no ha bastado para cubrir nuestras carnes [...] Todo lo hemos perdido hasta el dinero en la suma de 150 duros, que habíamos anticipado al capitán de la nave que debía llevarnos a Buenos Aires, comprendiendo en ellos la pensión de esta última parte del año; y en consecuencia nos vemos obligados a vivir de limosna todo el tiempo que queda del año. ${ }^{75}$

Después de varios meses de insistencia, tiempo en que «para vivir y alimentarnos, andamos mendigando de aquí y allí la comida», a comienzos del mes de enero de 1799 se remite la orden a Málaga para que se les otorgue mil reales y además se les habilita para poder cobrar la pensión. Vidaurre llegó a Buenos Aires a comienzos de marzo de 1800 y en el mes de julio de ese año a Santiago de Chile, ${ }^{76}$ donde reside por algunos meses acogido en un convento de monjas, para después trasladarse a una chacra en las proximidades de Concepción que había heredado de su familia. ${ }^{77}$ Otros cuatro jesuitas que aprovecharon estos meses para volver a Chile, pues la corte después comenzó a restringir los pasaportes y se hizo casi imposible retornar a sus lugares de origen, fueron Francisco Caldera, Juan José González, Domingo Valdés Carrera y Juan Crisóstomo Aguirre. ${ }^{78}$

74 Hanisch, 1972, 137.

75 Idem.

76 Ibidem, 138.

77 Ibidem, 229. Medina, 1906, 367. Enrich, 1891, II, 523-524. Esta chacra probablemente se ubicaba en las cercanías de Penco, que era la «patria» de Vidaurre según Diego León de Villafañe, un sacerdote que estaba de visita en Santiago para el tiempo de la repatriación de los ex jesuitas chilenos. Hanisch, 1972, 145. En Penco Pedro de Valdivia fundó el 5 de octubre de 1550 la antigua ciudad La Concepción de María Purísima del Nuevo Extremo, pero después del terremoto del 24 de mayo de 1751 que destruyó la ciudad, como también Chillán, Cauquenes, Curicó y Talca, las autoridades decidieron trasladarla al Valle de la Mocha, su actual ubicación. El repoblamiento de Penco comenzó recién en 1840. Vidaurre plasma en su libro la violencia de este terremoto que presenció siendo un niño: «El último, y de que puedo hablar como testigo ocular [...] arruinó enteramente la Concepción, no quedando en ella edificio alguno que pudiese servir a su dueño: impelió el mar contra ella, que la bañó enteramente por tres veces, y sacando cuanto precioso tenía, la dejó una de las pobres poblaciones del Reino». Vidaurre, 1889, I, 66.

78 Hanisch, 1972, 138,139. 
Una nueva complicación surge en la vida de Vidaurre en febrero de 1800 cuando el gobernador de Chile, Joaquín del Pino Sánchez de Rozas Romero y Negrete, informa a la corte que han llegado los ex jesuitas Francisco Caldera y Juan José González sin otro documento que el pasaporte. El 25 de marzo de 1801 la corte ordena el regreso inmediato a España de todos los ex jesuitas que se encontraban en Chile. Este mandato también disponía la detención de los ex jesuitas en el cuartel de San Pablo de Santiago. En Chile se alegó que los jesuitas estaban enfermos y no podían realizar el viaje de vuelta. Incluso, el Dr. Sánchez — dice Hanisch-, fiscal que llevaba el caso, pide que no se le exija la reclusión, proponiendo una fianza e invocando que en la orden no se aclaraba cómo hacer esa diligencia y también la religiosa y buena conducta de los padres. El 14 de diciembre de 1801 la Audiencia de Chile decidió que los jesuitas solo tuvieran reclusión en sus propias casas. $^{79}$

Unos días antes de esta resolución de la Audiencia a Vidaurre se le había notificado que debía presentarse a la brevedad en Santiago. El jesuita, que había sido diagnosticado de parálisis por Juan Campa, médico del batallón de infantería de Concepción y de «parálisis del lado izquierdo, fruto de los insultos apopléticos, que suelen repetirle» por Fulgencio Rodenas, responde que como vive en el campo y está únicamente por casualidad en Concepción, necesita la pensión para pagar las ropas que ha mandado a hacer y otras deudas que ha contraído en la ciudad. En la administración de las temporalidades jesuitas de Santiago se revisó su caso y se dictaminó que le debían once meses. Vidaurre en ese intertanto se resintió de su salud, por lo que pidió un plazo para recuperarse. Según los informes proporcionados por el médico Juan Rodenas y el presbítero Juan Fermín Gómez de Vidaurre, sobrino del jesuita, su estado de salud para 1802 no había mejorado. En agosto de 1803 la Real Audiencia decide informar al rey de las enfermedades de los ex jesuitas, ${ }^{80}$ por lo que vuelve a solicitar informes médicos. De la hemiplejia de Vidaurre esta vez informa el doctor en cirugía de Concepción Freeman Crowell. ${ }^{81}$

79 Ibidem, 140,141.

80 Los partes médicos de los otros jesuitas indicaban que: Juan José González presentaba indigestiones, cardialgias, frecuente reumatismo y cálculos a los riñones; Francisco Caldera tenía un asma humoral, habitual y convulsiva que lo ponía en peligro de muerte; Domingo Valdés Carrera sufría de hemoptisis, que se le presentaba en cualquier situación que alterara su ánimo; Juan Crisóstomo Aguirre presentaba deterioros de salud por ser octogenario. Ibidem, 141-143.

81 Ibidem, 142,143. 
Los inconvenientes para los jesuitas comienzan a solucionarse el 2 de enero de 1804, fecha en que se suspende el decreto que exigía el regreso a España, principalmente por la imposibilidad de ponerse de regreso. ${ }^{82}$ Otra cuestión que trajo mayor tranquilidad a los expulsos fue la regularización del pago de sus pensiones, que se hizo con cierta normalidad hasta $1814 .{ }^{83}$ En el caso de Vidaurre, todo indica que permaneció más tiempo en Concepción, dedicado principalmente al ministerio sacerdotal. Se ha dicho que en esta ciudad tuvo una destacada participación en la lucha por la independencia, incluso mayor que la del prócer local Juan Martínez de Rozas, figura ilustre de la emancipación chilena e inspirador y amigo de Bernardo O'Higgins. Se supone que Vidaurre aprovecharía su labor en la Iglesia para influir en los fieles y sacerdotes que se acercaban a consultarle acerca de las ideas que circulaban sobre independencia y autonomía, pues desde un primer momento manifestó su adhesión por la causa independentista, y cooperó «públicamente a impulsar el movimiento de opinión, que preparó la instalación de la Junta gubernativa del 18 de Septiembre de $1810 »{ }^{84}$

Esta destacada participación le habría costado una nueva detención y prisión al jesuita, primero en la catedral de Concepción y luego en la isla Quiriquina ${ }^{85}$ Este nuevo arresto se enmarca en el ataque del 13 de abril de 1813 de las tropas realistas a la ciudad de Concepción, una de las incursiones militares que antelaría el periodo de la historia de Chile conocido como la reconquista española (1814-1817). Ese día, el brigadier español Gabino Gaínza desobedeciendo uno de los acuerdos tomados anteriormente con los ciudadanos de la ciudad para su rendición, mandó detener a alrededor de doscientos vecinos (grupo en el que habría estado Vidaurre), casi todos acomodados e influyentes y que a su juicio parecían peligrosos. ${ }^{86}$ Por una de las cláusulas del Tratado de Lircay, ${ }^{87}$ los detenidos fueron liberados, pero

82 Para esta fecha Juan Crisóstomo Aguirre ya había fallecido.

83 Hanisch, 1972, 144.

84 Muñoz, 1915, 335-336.

85 Hanisch, 1972, 71. Esta pequeña isla que está ubicada a 11 kilómetros de la bahía de Concepción volvió a ser utiliza como prisión política por la dictadura chilena desde el 11 de septiembre de 1973 hasta abril de 1975. Hanisch $(1974,187)$ señala que Vidaurre fue desterrado a la Isla Mocha, situada frente a las costas de la provincia de Arauco en la VIII Región del Biobío.

86 Amunátegui, 1912, 474-475.

87 Este fue un tratado entre las fuerzas realistas y los representantes del gobierno chileno firmado el 3 de mayo de 1814 a las orillas del río Lircay, en las cercanías de Talca. Una de sus cláusulas disponía que los patriotas chilenos reafirmaban su lealtad a Fernando VII, considerando a Chile como parte de la monarquía española. Este acuerdo no fue respetado por ninguna de las partes y alcanzó a durar solo unos meses. 
solo por un breve tiempo, pues la mala defensa llevada por un ilustre vecino que pretendía congraciarse con las nuevas autoridades españolas los llevó a ser declarados reos de lesa majestad. ${ }^{88}$

Aunque parece no existir información que pueda confirmarlo, Vidaurre habría formado parte de un grupo de patriotas que la noche del 12 de abril de 1817 llegó con vida a las costas de Talcahuano luego de fugarse de la prisión en la Quiriquina. Este escape, que se realizó en endebles embarcaciones, estuvo forzado por las míseras condiciones en que quedaron los prisioneros tras la retirada de los guardias españoles de la isla. ${ }^{89}$ Ya en Concepción y considerando la violenta situación política de la época, como también su avanzada edad y frágil salud, habría hecho su testamento. ${ }^{90}$

Según Walter Hanisch, Vidaurre murió el 11 de enero de 1818 «en la retirada de los patriotas de Concepción al llegar a Cauquenes». ${ }^{91}$ Hanisch agrega además que «murió de un balazo» y que al momento de ser herido habría gritado: «iMuerte de Vidaurre!». ${ }^{92} \mathrm{Si}$ bien el historiador jesuita no apunta la fuente de esta notable información, es posible que esto aconteciera así, principalmente si se tiene en cuenta que la evacuación hacia el norte del Maule ordenada por O'Higgins a los cerca de 50.000 vecinos de Concepción —entre los que se contaba Vidaurre—, sin dejar nada que pudiera servir a las tropas realistas que se aprestaban a desembarcar en Talcahuano, fue muy violenta, pues además de algunos fusilamientos a realistas y la fuga de algunas familias españolas, esta gran caravana de personas que comenzó a salir de la ciudad el primer día de enero de 1818, si bien avanzaba resguardada por las tropas patriotas, sufrió ataques armados continuos de los realistas y de bandoleros.

La partida de defunción de Vidaurre, que agrega Hanisch, dice así:

En la Villa de Cauquenes de Nuestra Señora de la Mercedes de Manso en once días del mes de enero de 1818 hice entierro mayor cantado en la parroquia del cuerpo del presbítero don Felipe Vidaurre, de edad ochenta y seis años, murió en la emigración. Se ignoran sus padres. Se confesó, recibió el viático y la santa unción, de que doy fe: Pedro Pascual Rodríguez. ${ }^{93}$

88 Amunátegui, 1912, 475-476.

89 Barros Arana, 1884-1902, XI, 133-135.

90 Enrich, 1891, II, 523.

91 Hanisch, 1972, 229.

92 Hanisch, 1974, 187.

93 Ibidem, 229. Hay que corregir que Vidaurre falleció a los 87 años. 


\section{Conclusiones}

Es importante señalar antes de finalizar este trabajo que la obra de Vidaurre ha tenido la desdicha de ser siempre comparada con la de su colega Juan Ignacio Molina, uno de los más importantes sabios que ha tenido Chile a lo largo de su historia. Esto es tan evidente, que en la propia «Introducción» de la Historia geográfica, natural y civil del Reino de Chile, José Toribio Medina agrega unas notas de Rodolfo Philippi para la parte consagrada a la historia natural en la obra del expulso, en las que el naturalista alemán radicado en Chile comienza demostrando una serie de errores de Vidaurre, ocasionados casi siempre, según Philippi, por seguir los yerros de Molina. A la inversa, cuando intenta dar cuenta de unos de los pocos aciertos que descubre en la obra, por ejemplo, la forma genérica de los indígenas de Chile para denominar las legumbres $(\operatorname{deg} u l)$, señala que «esto sería un dato precioso si no fuese acaso sacado de Molina». ${ }^{94}$ Las críticas para los libros dedicadas a la parte civil en esta «Introducción», Medina las extrae principalmente de la historia de Diego Barros Arana, que en parte hemos mostrado en este trabajo. Como se podrá entender, nada menos elogioso para la obra del expulso, así como en nada atrayente para el futuro lector, que el estudio introductorio de su primera y única edición contenga impresiones poco alentadoras — por no decir descalificadoras, en el caso de Barros Arana- de dos de los más importantes eruditos de la época en Chile.

En este trabajo se ha intentado continuar la línea crítica y revisionista de los ensayos de Eduardo Solar Correa (1933) y de Fernando Casanueva (2001), autores cuyos trabajos están distanciados por varias décadas, pero posiblemente los únicos consagrados enteramente al estudio de la obra de Felipe Gómez de Vidaurre. Este manifiesto abandono que ha mantenido la crítica especializada con la Historia geográfica, natural y civil del Reino de Chile, así como con su autor, probable mártir ilustre de la independencia chilena, pero tan exiguamente investigado que se hace casi imposible afirmar alguna fecha o dato de su biografía, puede deberse principalmente a la desvalorización que hizo de esta obra la historiografía chilena del siglo XIX, en particular Diego Barros Arana, uno de sus máximos representantes.

Si bien el manuscrito original del jesuita expulso por lo menos merecía una revisión más acuciosa que ayudara a mejorar en parte eso de no poseer «una pluma fácil», ${ }^{95}$ su libro puede ser considerado rico en descripciones

94 Medina, 1889, XIX-XX.

95 Solar Correa, 1969, 197. 
y en ciertos juicios que sugieren estar en presencia de un observador singular para su tiempo, incluso hasta adelantado y tomando ribetes de historia social, particularmente en los libros que dedica a los mapuches y a la elite criolla. A diferencia de Barros Arana, creemos que la obra del expulso sería un valioso aporte al mayor conocimiento del pasado colonial, principalmente del periodo que precede a la independencia, y una mayor difusión de este libro, en lo posible en una nueva edición crítica, así como un mejor examen realizado por los nuevos especialistas, contribuiría a reconstruir ese importante periodo de la historia de Chile y de América Latina.

Sin embargo, el mejor estudio y valoración de la Historia geográfica, natural y civil del Reino de Chile y de Felipe Gómez de Vidaurre no estarían completos si no se tienen en cuenta sus otras obras, por lo que se hace necesaria la publicación de los manuscritos (que se encuentran únicamente en Madrid) de Conversaciones familiares de un Padre americano con sus hijos Caupolicán y Colocolo, como también las investigaciones que ayuden a establecer que el «Compendio anónimo» es una obra de su autoría o al menos compartida con Molina. Esto, que pondría a Vidaurre como uno de los escritores más prolíficos del periodo colonial chileno, también posibilitaría relacionar en conjunto la línea argumentativa de este pensador jesuita de finales del siglo XVIII respecto a Chile.

Recibido el 6 de agosto de 2015 Segunda versión el 7 de marzo de 2016 Aceptado el 18 de marzo de 2016

\section{Referencias bibliográficas}

Álvarez Arregui, Federico, «El debate del Nuevo Mundo», en Pizarro, Ana (ed.), América Latina. Palavra, Literatura e Cultura, Volume 2, Emancipação do discurso, Sao Paulo-Campinas, Memorial-Unicamp, 1994, 36-66.

Amunátegui, Miguel Luis y Amunátegui, Gregorio Víctor, La reconquista española, Santiago de Chile, Imprenta, Litografía i Encuadernación Barcelona, 1912.

Barros Arana, Diego, Historia jeneral de Chile, Santiago de Chile, Rafael Jover, 1884-1902, 16 volúmenes.

Batllori, Miguel, El abate Viscardo. Historia y mito de la intervención de los jesuitas en la independencia de Hispanoamérica, Madrid, Mapfre, 1995.

Casanueva, Fernando, «Felipe Gómez de Vidaurre: un jesuita expulso, chileno y patriota», en Tietz, Manfred y Briesemeister, Dietrich (eds.), Los Jesuitas 
españoles expulsos: su imagen y su contribución al saber sobre el mundo hispánico en la Europa del siglo XVIII, Madrid, Iberoamericana, 2001, 207-235.

Enrich, Francisco, Historia de la Compañía de Jesús en Chile, Barcelona, Imprenta de Francisco Rosal, 1891, 2 vols.

Espinosa Pólit, Aurelio, Los jesuitas quiteños del extrañamiento, [1960], Quito, Biblioteca Ecuatoriana Clásica, 1989.

Figueroa Zúñiga, Marcos A., «El gentilicio para los habitantes de Chile en Juan Ignacio Molina», Revista de Crítica Literaria Latinoamericana, 67, 2008, 95-110.

Figueroa Zúñiga, Marcos A., «Histórica Relación del Reino de Chile de Alonso de Ovalle. Un ejemplo de la lenta adquisición de una conciencia criolla en el Chile del siglo XVII», en Santos Herceg, José (comp.), Nuestra América inventada: Imágenes de América Latina en los pensadores chilenos, Santiago de Chile, RIL Editores, 2012, 21-51.

Foerster, Rolf, Jesuitas y Mapuches 1593-1767, Santiago de Chile, Editorial Universitaria, 1996.

Hachim Lara, Luis, «Narrativa de indios en las Historias naturales de Juan Ignacio Molina y Felipe Gómez de Vidaurre», América sin Nombre, 18, 2013, 95-103.

Hanisch, Walter, Itinerario y pensamiento de los jesuitas expulsos de Chile (17671815), Santiago de Chile, Editorial Andrés Bello, 1972.

Hanisch, Walter, Historia de la Compañía de Jesús en Chile, Buenos Aires, Editorial Francisco de Aguirre, 1974.

Hanisch, Walter, Juan Ignacio Molina, sabio de su tiempo, Santiago de Chile, Ediciones Nihil Mihi, 1976.

Koselleck, Reinhart, historia/Historia, [1975], traducción e introducción de Antonio Gómez Ramos, Madrid, Mínima Trotta, 2004.

Lynch, John, Las revoluciones hispanoamericanas 1808-1826, [1973], España, Ariel, 2010.

Medina, José Toribio, Historia de la literatura colonial de Chile, Santiago de Chile, Imprenta de la Librería del Mercurio, 1878, 3 vols.

Medina, José Toribio, «Introducción», en Vidaurre, Felipe Gómez de, Historia geográfica, natural y civil del Reino de Chile, Santiago, Imprenta Ercilla, 1889, tomo I, IX-XXII.

Medina, José Toribio, Diccionario Biográfico Colonial, Santiago de Chile, Imprenta Elzeviriana, 1906.

Medina Rojas, Francisco de Borja, «Extrañamiento y extinción de la Compañía de Jesús: venturas y desventuras de los jesuitas en el exilio de Italia», en Marzal, Manuel y Bacigalupo, Luis (eds.), Los jesuitas y la modernidad en Iberoamérica 1549-1773, Lima, Fondo Editoral PUCP, Instituto Francés de Estudios Andinos, Universidad del Pacífico, 2007, 450-492. 
Muñoz Olave, Reinaldo, El Seminario de Concepción durante la Colonia y la revolución de la Independencia (1572-1813), Santiago de Chile, Imprenta San José, 1915.

Olivares, Miguel de, Historia militar, civil y sagrada del Reino de Chile, [1762], Colección de Historiadores de Chile y de Documentos Relativos a la Historia Nacional, Tomo IV, Santiago, Imprenta del Ferrocarril, 1864.

Retamal Ávila, Julio, «Fidelidad conyugal en el Chile colonial», en Sagredo, Rafael y Gazmuri, Cristián (dirs.), Historia de la vida privada en Chile. Tomo I. El Chile tradicional. De la Conquista a 1840, Santiago, Taurus-Aguilar Chilena de Ediciones, 2005, 46-69.

Roig, Arturo Andrés, Teoría y crítica del pensamiento latinoamericano, [1981], 2. ${ }^{\text {a }}$ edición, Buenos Aires, Una Ventana, 2009.

Ronan, Charles E. S.J., y Hanisch, Walter S.J, Epistolario de Juan Ignacio Molina S.J., Santiago de Chile, Editorial Universitaria, 1979.

Solar Correa, Eduardo, Semblanzas Literarias de la Colonia, [1933], 3. a edición, Buenos Aires, Editorial Francisco de Aguirre, 1969.

Tampe, Eduardo, Catálogo de Jesuitas de Chile 1593-1767. Catálogo de Regulares de la Compañía en el antiguo Reino de Chile y en el destierro, Santiago de Chile, Universidad Alberto Hurtado, 2008.

Vidaurre, Felipe Gómez de, Historia geográfica, natural y civil del Reino de Chile, [1782], Colección de Historiadores de Chile y de Documentos Relativos a la Historia Nacional, XIV y XV, Santiago, Imprenta Ercilla, 1889, 2 tomos. 